\title{
Prenatal and Perinatal Factors Influencing Nociception, Addiction and Behavior during Ontogenetic Development
}

\author{
R. ROKYTA, A. YAMAMOTOVÁ, R. ŠLAMBEROVÁ, M. FRANĚK, Š. VACULÍN, \\ L. HRUBÁ, B. SCHUTOVÁ, M. POMETLOVÁ
}

Charles University in Prague, Third Faculty of Medicine, Department of Normal, Pathological and Clinical Physiology, Prague, Czech Republic

Received February 15, 2008

Accepted April 16, 2008

On-line May 13, 2008

\section{Summary}

This review, which summarizes our findings concerning the longterm effects of pre-, peri- and postnatal factors affecting development, nociception and sensorimotor functions, focuses on three areas: 1) perinatal factors influencing nociception in adult rats were examined in rats with hippocampal lesions, after the administration of stress influencing and psychostimulant drugs (dexamethasone, indomethacine and methamphetamine); 2) the effect of pre- and early postnatal methamphetamine administration was shown to impair the development of sensorimotor functions tested in rat pups throughout the preweaning period; 3 ) the effect of extensive dorsal rhizotomy of the brachial plexus during the early postnatal period was studied with respect to neuropathic pain development and sensorimotor functions. The present study indicates that prenatal or neonatal stress, as well as various drugs, may disturb the development of the nociceptive system and cause long-term behavioral changes persisting to adulthood and that some types of neuropathic pain cannot be induced during the first two postnatal weeks at all. A mature nervous system is required for the development of the described pathological behaviors.

\section{Key words}

Nociception • Hippocampus • Methamphetamine • Rhizotomy • Ontogeny

\section{Corresponding author}

R. Rokyta, Department of Normal, Pathological a Clinical Physiology, Third Faculty of Medecine, Charles University, Ke Karlovu 4, 12000 Prague 2, Czech Republic. E-mail: richard.rokyta@lf3.cuni.cz

\section{Introduction}

It is generally accepted that the prenatal, perinatal and early postnatal periods are crucial and decisive for further ontogenetic development (Horn 1987, Campbell 1984). However, with respect to specific experimental conditions and the different mechanisms involved in the studied pathological symptoms and syndromes, it is possible to solve these mechanisms only partially. Therefore, we focused on: 1) the perinatal effects of several factors that could influence nociception in adult rats; 2) the development of chronic neuropathic pain in the early postnatal period; and 3 ) the development of sensorimotor functions in prenatally methamphetamine (MA)-treated rats.

\section{Perinatal factors influencing nociception in adult rats}

The developing nociceptive system is under the control of multiple endogenous and exogenous factors, e.g. neurotransmitters, neuromodulators, maternal care, maternal separation, prenatal stress, fostering and preand postnatally applied therapeutic or abused drugs.

Drugs administered in the perinatal period may interfere with gene expression during the determined program of developmental processes and thus disorganize perinatal ontogenesis, which is characterized by intensive cell differentiation and receptor formation in already 
shaped organs (e.g. brain, immune and endocrine organs). These disturbances on the cellular or subcellular level are not evident at birth, but become apparent during further development and maturation as various neuro-psychobehavioral deviations.

All mediator systems that are involved in either pain transmission in the spinal cord (e.g. glutamate, substance $\mathrm{P}$ ), pain suppression in the descending antinociceptive system (e.g. serotonin, noradrenalin, endorphins, enkephalins) or pain processing at the level of limbic or cortical structures (e.g. dopamine, endogenous opioids and cannabinoids) should be affected by perinatal manipulations.

Rats prenatally exposed to morphine exhibit greater tail-flick baseline values and higher analgesia in response to morphine challenge compared with control animals (Gagin et al. 1996). In adult rats prenatally exposed to morphine, increased withdrawal latency to thermal stimuli and an enhanced analgesic effect of morphine are also accompanied by a weaker effect of anxiolytic drugs (Voronina et al. 1994). These findings indicate that prenatal morphine induces long-lasting alternations in the opioid and serotonergic systems.

Selective serotonin reuptake inhibitors (SSRI) are widely used to treat antenatal and postpartum depression. Oberlander et al. (2005) found that infants with prenatal and postnatal SSRI exposure had diminished facial and cardiac autonomic responses to the pain of a heel-lance at 2 months of age. The observed blunted pain reactivity may reflect an increased or altered capacity to modulate pain signals as all SSRI are thought to increase synaptic serotonin concentration in the brain.

In our previous studies we evaluated the changes in nociceptive sensitivity to two drugs used in obstetrics and neonatology: indomethacin, given to risk newborns to prevent intraventricular haemorrhage or to accelerate the closure of patent ductus arteriosus, and dexamethasone, prescribed for the induction of surfactant production in immature fetal/neonatal lungs and thus for the prevention/treatment of neonatal respiratory distress syndrome. The experiments have shown that alterations in nociception appeared only following drug administration at a later stage of ontogenetic development (i.e. postnatal day (PD) 9-10). Indomethacin administration increased the sensitivity to thermal stimulus in 3-month-old rats; however, in old animals (12 months) these differences from controls disappeared. On the other hand, adult rats exposed to dexamethasone at PD9-10 revealed no changes in nociception at the age of 3 months, but at the age of 12 months they showed decreased sensitivity in the plantar test and the tail-flick test (Benešová et al. 2001a,b). It could be assumed that the increase of latencies in old dexamethasone rats indicates an earlier onset of aging processes (Gagliese and Melzack 2000).

The last week of embryonic life and the first two postnatal weeks are critical periods in the development of the dopaminergic and serotoninergic systems at which time they could be particularly vulnerable to injury (Galineau et al. 2004). The dopamine and serotonin transporters are also targets of many psychoactive drugs such as MA.

MA is a psychostimulant drug that acts on the central nervous system through a non-exocytotic mechanism, causing the release of monoamine neurotransmitters, including dopamine, noradrenaline and serotonin. Serotonin significantly influences the maturation of dendrites and synaptogenesis and plays a role in the regulation of brain development (WhitakerAzmitia 2001).

As information about nociception in adulthood in prenatally MA-exposed humans as well as animals is missing, the aim of our experiments was to study this effect in adult Wistar rats whose mothers were exposed daily to stress (injection of saline) or to MA, either during their entire pregnancy or during pregnancy and lactation. MA and prenatal stress influenced nociception in adult male and female rats differently. It was found that females were more sensitive to the MA challenge to the mother and developed an increased sensitivity to pain, whereas males were more sensitive to prenatal stress without MA and developed a decreased sensitivity to pain (Yamamotová et al. 2004). These results are in agreement with other studies showing gender differences in the impact of prenatal and postanatal stress on the magnitude of stress-induced opioid and non-opioid mediated antinociception in mice (Sternberg and Ridgway 2003).

The longer latencies observed in males born to mothers stressed with saline injections might reflect more intensive prenatal stress when compared with MA-exposed males. Although the stress intensity from a daily injection of MA or saline should be similar in both groups, MA might attenuate the physiological impact of acute stress (Söderpalm et al. 2003). Activation of dopamine receptors stimulates HPA-reactivity in rats, whereas glucocorticoids facilitate dopaminergic activity. However, when volume and cell number in the nucleus accumbens of adult offspring born to mothers who were 
repeatedly stressed in mid-pregnancy by the injection of either saline or amphetamine were compared, no differences were found. Both groups had equally reduced volumes in comparison with intact controls (McClure et al. 2004).

The involvement of the hippocampus in pain processing has been described in several experimental studies and clinical observations in humans as well as in adult experimental animals (Hebben et al. 1985, Ploghaus et al. 2001). Less is known about the role of the hippocampus in nociception during development. A neonatal hippocampal lesion induced by ibotenic acid decreased latency in the hot plate and paw pressure tests (both supraspinally modulated), although no effect was observed in the tail flick test, which is mediated mostly at the spinal level (Al Amin et al. 2004). In another study focusing on postnatal hippocampal lesions, it was demonstrated that the behavioral outcomes of such lesions in rats are determined by early postnatal environmental variables, including social interactions (Wood et al. 2001).

Changes in the glutamatergic system resulting from neonatal brain infusion of quinolinic acid (QUIN) and/or $N$-acetyl-L-aspartyl-L-glutamate (NAAG) are thought to be important in animal models of schizophrenia. Comparing the two types of hippocampal lesions, we found that the perception of pain in these animals was influenced in different ways. Neonatal intracranial infusion of quinolinic acid did not change basal thermal nociception when compared with intact animals. The application of NAAG also did not significantly change nociception if compared with intact animals, but the latencies were longer than in QUINtreated animals. Contrary to our expectation, significant differences were observed between sham-operated rats living with QUIN-treated animals and those living with NAAG-treated animals. Our results show that social factors, which were originally demonstrated only in pain behavior, might also influence basal nociceptive sensitivity in rats (Yamamotová et al. 2007).

Nociceptive sensitivity should not be considered exclusively innate even if the animals housed together are siblings, because identical changes were observed in rats coming from different families. These results suggest the possibility of transferring some patterns of behavioral abnormalities (including pain sensation) from more pathologic individuals to more vulnerable ones during the period of pre-adolescent development.

Our experiment with cross-fostering in prenatally
MA-treated rats and prenatally saline-treated (stressed) rats showed that nociceptive sensitivity is dependent on social factors and therefore can be affected by the quality of maternal care (Yamamotová and Šlamberová 2005). Prenatally MA-treated male rats fostered by adoptive stressed mothers had higher sensitivity to pain then prenatally stressed rats fostered by MA mothers. Rats fostered by their own mothers did not differ in nociception. Differences in nociception in rats fostered by adoptive mothers might result from changed stress reactivity, which has long-term consequences on their behavior and emotionality. Repeated maternal separation during the first week of life also alters the antinociceptive effect of morphine. Maternally separated rats exhibited exaggerated behavioral and neuroendocrine responses to stress in adulthood in comparison with controls, and the antinociceptive effect of morphine was less potent. However, this effect was observed in the hot-plate test but not in the tail-flick test (Kalinchev et al. 2001).

The observed results support the hypothesis that variation in rat maternal care could serve as a mechanism for a non-genomic behavioral mode of the transmission of traits.

\section{Effect of perinatal MA exposure on the sensorimotor development of rat pups}

One of the most serious problems of the present day is drug, alcohol, and nicotine abuse. The percentage of drug abusers is growing from year to year and their age is getting lower. While many clinical and experimental studies have investigated behavioral and biological changes in drug-abusers, there is not much known about the effect of drug abuse in pregnant women and the possible long-term effects of prenatal drug-exposure on their progeny during development and in adulthood. However, statistics show that the number of infants with drug-related birth defects has increased dramatically over the past several years (Marwick 2000). Drugs easily cross the placental barrier and therefore may affect the development of the fetus. Furthermore, the newborns may also receive these drugs postnatally in the mother's breast milk. The drug abuse of pregnant women and mothers is therefore not only a serious social problem, but also a serious health problem that is necessary to deal with.

Beside direct effects, drugs also have indirect ones. It was shown that drug-abusing women are less scrupulous in the prenatal as well as the postnatal care of their children (Vavř́nková et al. 2001). Ninety percent 
are single mothers and generally deliver at younger ages than mothers who do not abuse drugs. They are often unemployed women with economic and social problems and are not able to take good care of their children. This usually results in the legal system's removing the child from the drug-abusing mother. All of this may lead to psychological deprivation and the mental retardation of the child. Thus, not only drug abuse itself, but also worse maternal care may induce irreversible changes in the development of children.

In agreement with clinical works, experimental studies (Bridges et al. 1982, Fraňková 1977, Šlamberová et al. 2001, 2003, 2005, 2007) demonstrated that rat mothers who received drugs during the period of gestation and/or lactation displayed decreased maternal behavior toward their pups. In addition, our and other studies have shown that perinatal drug exposure impairs the postnatal development of rat pups (Acuff-Smith et al. 1996, Martin et al. 1976, Šlamberová et al. 2005, 2006, 2007). The extent of the drug-induced effect and the extent of the effect induced by decreased maternal care on healthy pup development remain, however, unclear.

Postnatal care plays an important role in the emotional and cognitive development of children. Physical and emotional deprivation and family conflicts may induce long-term consequences in the postnatal development of a child (Meaney 2001). Children who have been exposed to abuse or neglect are more likely to develop numerous psychopathologies, such as anxiety, mood disorders and psychosis, that might persist throughout life (Bebbington et al. 2004). In mammals, the mother is the principal caregiver, providing both nutritional resources and behavioral stimulation to her offspring. In the rat, maternal care during the first week of postnatal life, particularly licking/grooming (LG), influences hippocampal development and function (Liu et al. 2000). Liu et al. (2000) showed that the offspring of mothers who exhibited a higher frequency of LG over the first week of postnatal life had increased hippocampal synaptic density and enhanced spatial learning and memory. In addition, Meaney (2001) found that female rat pups that received increased maternal care were also „better mothers“ in adulthood than female offspring of mothers exhibiting neglectful maternal behavior. Thus, it was shown that postnatal care plays an important role in the development of offspring. The question, however, is whether maternal care may improve the drug-induced impairment of postnatal development.

There are only a few studies showing the effect of cross-fostering on the postnatal development of offspring exposed prenatally to a drug or alcohol. In alcohol studies, Lancaster et al. (1984) demonstrated that the offspring of control dams cross-fostered during lactation to ethanol-treated dams had abnormal organ weights, abnormal brain weights and severely depressed brain myelin concentrations. Vorhees (1989) showed that fostered offspring oriented to their home cage scent less than did cross-fostered offspring and also that crossfostered animals were more active than fostered animals in an open field test. Murillo-Fuentes et al. (2001) showed that chronic alcohol administration during gestation and/or lactation adversely affects pup growth prior to weaning as indicated by its effect on milk consumption, pup and organ weight.

There are no studies available that would show how maternal care may affect the postnatal development of animals prenatally exposed to drugs. Our most recent results (Hrubá et al. 2008) indicate that prenatal and postnatal MA exposure impairs the postnatal development of rat pups, especially sensorimotor functions and postural reflexes. Our previous studies (Šlamberová et al. 2006, 2007) showed that MA administered during prenatal and/or preweaning periods alters the functional development of rat pups and also that it alters two generations of offspring. This impairing effect of MA seems to be improved by postnatal care from control mothers. Specifically, prenatally MAexposed pups fostered by control dams were significantly better in a righting reflex test on a surface and a rotarod test than either prenatally or postnatally MA-exposed pups. Prenatally MA-exposed pups fostered by controls or saline-exposed dams were faster in righting than either prenatally or postnatally MA-exposed pups. Further, in the rotarod test, prenatally MA-exposed animals fostered by controls or saline-exposed dams displayed a similar time on the rotating cylinder relative to controls or salineexposed pups. In a negative geotaxis test, pups prenatally exposed to MA and raised by control mothers had a faster latency of turning, but these result were not significant (Hrubá et al. 2008).

On the other hand, our data (Hrubá et al. 2008) demonstrate that control pups postnatally exposed to MA displayed worse results in all tests than did controls or prenatally saline-exposed pups fostered by controls or saline-exposed pups. The ability of pups to right themselves on a surface and in mid-air was worse in control pups postnatally exposed to MA than in controls or prenatally saline-exposed pups fostered by controls or 
saline-exposed dams. Control pups that were fostered by MA-treated mothers spent less time on the rotating cylinder and had longer latency of turning in negative geotaxis test than control pups fostered by control mothers.

A possible explanation of the impairing effect of drugs and alcohol on sensorimotor functions might be alterations in myelin development. This hypothesis is supported by the findings of Lancaster et al. (1984), who demonstrated an impairing effect of ethanol administered during gestation and lactation on myelin development. When animals born to dams consuming ethanol during gestation were cross-fostered to control dams at birth, myelin development was comparable to that of the offspring of pairfeds and well-nourished controls. On the other hand, when the pairfed or nourished pups were cross-fostered at birth to lactating dams consuming ethanol, myelin development was more severely depressed than myelin development in pups crossfostered to pairfed lactating dams.

Thus, it seems that the postnatal care provided by a control mother at least partially improves the development of rat pups prenatally exposed to drugs.

\section{Chronic pain in the early postnatal period}

Neuropathic pain is known to appear in infants and younger children, although the incidence is much lower than in school-age children and adults. The lesion of the nervous system can be either peripheral or central. Peripheral neuropathic pain in newborns and children consists mostly of complex regional pain syndrome, scar neuroma and phantom limb pain (Wilder et al. 1992, Ingelmo and Fumagalli 2004). Central neuropathic pain (Al Qattan 1999, Rossitch E Jr et al. 1992) in newborns and children consists mostly of brachial plexus lesions, which might evoke severe self-mutilation in total avulsion.

There are only a few papers dealing with the effect of total or partial deafferentation on pain during the postnatal period in rats (Vaculín et al. 2005, Howard et al. 2005, Lee and Chung 1996).

The brachial plexus is the most common site involved in upper extremity neuropathies in human neonates. The incidence of a brachial plexus lesion (BPL) in neonates varies between 0.03 and $1 \%$. BPLs in neonates have been traditionally divided into three groups according to the affected roots as follows: Erb's (C5-C6, ev. C7; most common), Klumpke (C8-Th1; the lowest incidence) and total (Dodds and Wolfe 2000). A BPL in neonates impairs sensory and motor functions and sometimes evokes self-mutilation, which is severe in patients with a total lesion and usually consists of biting the tips of the digits (Al Qattan 1999, Rossitch E Jr et al. 1992). The pathological mechanisms of these injuries remain unclear; however, high birth weight, shoulder dystocia and forceps-assisted deliveries have been identified as risk factors.

A model of brachial plexus avulsion - multiple dorsal rhizotomy in rats - was introduced by Basbaum (1974). A unilateral dorsal rhizotomy of the brachial plexus nerves (C5-T1 deafferentation) is known to induce self-mutilation in rats. There are conflicting views about the correlation between self-mutilation and pain sensation in animal models (Rodin and Kruger 1984). However, evidence points to the theory of self-mutilation as a behavioral correlate of pain sensation (Lombard et al. 1979, Mailis 1996, Sweet 1981, Vaculín and Rokyta 2004).

Total deafferentation, as a model of central neuropathic pain, has been performed in the early postnatal period in rats and, in general terms, the effect is much smaller than in adults (Vaculín et al. 2005). In terms of motor function, only occasional misplacement is noticeable. Sitting down on its hind legs, the rat keeps the deafferentated forelimb in extension, but when the forelimb is to be used again, no visible differences are noticed. Programmed behavior (grooming) is identical with that of intact animals. When feedback sensation from proprio- and exteroreceptors is not required for precise movement, no visible differences in movement can be observed.

In terms of pain syndrome, self-mutilation does not develop at all when total deafferentation is performed prior to PD 21; slight symptoms appear when the deafferentation is performed between PD 21 and PD 35, and selfmutilation similar to that observed in adults develops when the deafferentation is performed after PD 35.

Similar results were described by Howard et al. (2005) in two peripheral neuropathic pain models. They used spared nerve injury (SNI) and chronic constriction injury (CCI) models to observe pain development in rat pups. The SNI model is evoked by tight ligation and sectioning of two of the three branches (tibial and common peroneal nerves) of the sciatic nerve, while leaving the third branch (sural nerve) intact. SNI induces mechanical allodynia and other signs of neuropathic pain in adult animals (Decosterd and Woolf 2000). In contrast, 
SNI performed in animals aged 3, 10 or 21 days does not evoke allodynia. Only SNI performed at PD 33 or later leads to persistent allodynia with the threshold falling more than $50 \%$ of control values (Howard et al. 2005). $\mathrm{CCI}$ is evoked by four loose ligations placed around the sciatic nerve and induces mechanical and thermal allodynia and hyperalgesia in adult rats (Bennett and Xie 1988). In contrast, CCI evoked by the placement of three ligatures induces no changes in mechanical pain thresholds (Howard et al. 2005).

On the other hand, Lee and Chung (1996) described the development of mechanical allodynia in 7-, 14- and 21-day-old rats following spinal nerve ligation. Spinal nerve ligation is evoked by tight ligation of the L5 and L6 spinal nerves and triggers neuropathic pain behavior in adult rats (Kim and Chung 1992). When performed in the early postnatal period (in the youngest two groups), however, allodynia disappeared several weeks after the surgery in contrast to adults.

In all the described models, pain testing is based on motor performance. Therefore, it was suggested that the immaturity of the motor system prevents testing until 15 days of age since the rats cannot stand or walk before this time point. However, it was shown by many authors that a paw withdrawal reaction appeared even before that time. The first reflexive respond to somatic stimulation appears on the 15th gestational day in rats (Narayanan et al. 1971). At the same time spontaneous movement might be detected (de Vries et al. 1982). However, the stimulation is of a tactile or pressure nature rather than a nociceptive modality (Fitzgerald 1987). Rat pups are able to express pain behaviour immediately after birth. It was shown that pain behavior appears in one-day-old rat pups when exposed to a formalin test (Abbott and Guy 1995). Pain thresholds determined as a response to thermal and/or mechanical stimulation were demonstrated to be lowest on postnatal day 1, then the thresholds increase until PD 7 and remain unchanged afterwards (Tseng 1998). However, other authors described either a decrease in the latency to thermal nociceptive stimulation from PD 10 to PD 25 (Ba and Seri 1993) or peaks of minimal latency at PD 7 and maximal latency at PD 15 (Hassmannová and Rokyta 2002). Therefore, it seems very likely that the absence of paw withdrawal changes after the induction of peripheral neuropathic lesions is rather linked to factors involved in neuropathic pain development. These factors develop between the second and third postnatal weeks and might be attributed to sympathetic innervation, ectopic discharges, involved receptor immaturity, the descending pain inhibitory system, synaptic reorganization, and other causes (Lee and Chung 1996, Vaculín et al. 2005, Howard et al. 2005).

The central nervous system in the rat matures around the third postnatal week, and the maturation and rearrangement of NMDA receptor subunits and function occur around the 30th postnatal day (Alvares and Fitzgerald 1999, Fitzgerald and Jennings 1999, Gonzalez et al. 1993). In several studies (Vaculín and Rokyta 2004, Tseng 1998, Wong et al. 1998, Yoshimura and Yonehara 2006, Yashpal et al. 2001) it was shown that neuropathic pain in an adult rat is not likely to develop when the NMDA receptors have been blocked. Accordingly, it was suggested that the structural and functional rearrangement of NMDA receptors after birth might be one of the most important factors underlying neuropathic pain development in young animals (Vaculín et al. 2005).

\section{Conclusions}

From our results we can conclude that prenatal or neonatal stress, as well as various drugs, may disturb the development of the nociceptive system and cause longterm behavioral changes persisting to adulthood. The development of neuropathic pain behavioral symptoms in rats strongly depends on the period of nervous system injury, and a mature nervous system is required for the development of the described pathological behavior. However, we obviously do not know all the involved factors, and therefore further studies performed during the early postnatal period are required.

Future studies will investigate the effect of perinatal exposure on adult rats. Behavioral tests, such as the open field test, and tests of anxiety, such as the elevated plus-maze, will be used to detect long-term changes in behavior induced by perinatal drug exposure and the possible effect of maternal care. Because gonadal hormones have been shown to affect anxiety and behavior especially in female rats, both males and females (with consideration of the stage of their estrous cycle) will be used in all experiments.

\section{Conflict of Interest}

There is no conflict of interest.

\section{Acknowledgements}

Supported by CN LC554. 


\section{References}

ABBOTT FV, GUY ER: Effects of morphine, pentobarbital and amphetamine on formalin-induced behaviours in infant rats: sedation versus specific suppression of pain. Pain 62: 303-312, 1995.

ACUFF-SMITH KD, SCHILLING MA, FISHER JE, VORHEES CV: Stage-specific effects of prenatal dmethamphetamine exposure on behavioral and eye development in rats. Neurotoxicol Teratol 18: 199-215, 1996.

AL AMIN H, ATWEH SF, JABBUR S, SAADÉ NE: Effects of ventral hippocampal lesion on thermal and mechanical nociception in neonates and adult rats. Eur J Neurosci 20: 3027-3034, 2004.

AL QATTAN MM: Self-mutilation in children with obstetric brachial plexus palsy. J Hand Surg [Br ] 24: 547-549, 1999.

ALVARES D, FITZGERALD M: Building blocks of pain: the regulation of key molecules in spinal sensory neurones during development and following peripheral axotomy. Pain Suppl 6: S71-S85, 1999.

BA A, SERI BV: Functional development of central nervous system in the rat: ontogeny of nociceptive thresholds. Physiol Behav 54: 403-405, 1993.

BASBAUM AI: Effects of central lesions on disorders produced by multiple dorsal rhizotomy in rats. Exp Neurol $\mathbf{4 2}$ : 490-501, 1974.

BEBBINGTON PE, BHUGRA D, BRUGHA T, SINGLETON N, FARRELL M, JENKINS R, LEWIS G, MELTZER $\mathrm{H}$ : Psychosis, victimisation and childhood disadvantage: evidence from the second British National Survey of Psychiatric Morbidity. Br J Psychiatry 185: 220-226, 2004.

BENEŠOVÁ O, TEJKALOVÁ H, KRIŠTOFÍKOVÁ Z, HUŠEK P, NEDVÍDKOVÁ J, YAMAMOTOVÁ A: Brain maldevelopment and neurobehavioural deviations in adult rats treated neonatally with indomethacin. Eur Neuropsychopharmacol 11: 367-373, 2001a.

BENEŠOVÁ O, TEJKALOVÁ H, YAMAMOTOVÁ A: Neonatal drug exposure (indomethacine, dexamethasone) and nociception in young adult and aging rats. Psychiatrie 5 (Suppl 2): 8-10, 2001b.

BENNETT GJ, XIE YK: A peripheral mononeuropathy in rat that produces disorders of pain sensation like those seen in man. Pain 33: 87-107, 1988.

BRIDGES RS, GRIMM CT: Reversal of morphine disruption of maternal behavior by concurrent treatment with the opiate antagonist naloxone. Science 218: 166-8, 1982.

CAMPBELL BA, MISANIN JR, WHITE BC, LYTTLE LD: Species differences in ontogeny of memory: indirect support for neural maturation as a determinant of forgetting. J Comp Physiol Psychol 87: 193-202, 1974.

DE VRIES JI, VISSER GH, PRECHTL HF: The emergence of fetal behaviour. I. Qualitative aspects. Early Hum Dev 7: 301-322, 1982.

DECOSTERD I, WOOLF CJ: Spared nerve injury: an animal model of persistent peripheral neuropathic pain. Pain 87: 149-158, 2000.

DODDS SD, WOLFE SW: Perinatal brachial plexus palsy. Curr Opin Pediatr 12: 40-47, 2000.

FITZGERALD M, JENNINGS E: The postnatal development of spinal sensory processing. Proc Natl Acad Sci USA 96: 7719-7722, 1999.

FITZGERALD M: Prenatal growth of fine-diameter primary afferents into the rat spinal cord: a transganglionic tracer study. J Comp Neurol 261: 98-104, 1987.

FRAŇKOVÁ S: Drug-induced changes in the maternal behavior of rats. Psychopharmacology (Berl) 53: 83-87, 1977.

GAGIN R, COHEN E, SHAVIT Y: Prenatal exposure to morphine alters analgesic responses and preference for sweet solutions in adult rats. Pharmacol Bioch Behav 55: 629-634, 1996.

GAGLIESE L, MELZACK R: Age differences in nociception and pain behaviours in the rat. Neurosci Behav Rev 24: 843-854, 2000.

GALINEAU L, KODAS E, GUILLOTEAU D, VILAR M-P, CHALON S: Ontogeny of the dopamine and serotonin transporters in the rat brain: an autoradiographic study. Neurosci Lett 363: 266-271, 2004.

GONZALEZ DL, FUCHS JL, DROGE MH: Distribution of NMDA receptor binding in developing mouse spinal cord. Neurosci Lett 151: 134-137, 1993. 
HASSMANNOVÁ J, ROKYTA R: The postnatal development of tail-flick latencies to acute and repeated stimulation in the rat. Exp Physiol 87: 63-67, 2002.

HEBBEN N, CORKIN S, EICHENBAUM H, SHEDLACK K: Diminished ability to interpret and report internal states after bilateral medial temporal resection: case H.M. Behav Neurosci 99: 1031-1039, 1985.

HORN G: Imprinting: a neural analysis of learning and of a predisposition. In: Ontogenesis of the Brain, S. TROJAN, F. ŠŤASTNÝ, editor Universitas Carolina Pragensis, Praha 1987, pp 111-115.

HOWARD RF, WALKER SM, MOTA PM, FITZGERALD M: The ontogeny of neuropathic pain: postnatal onset of mechanical allodynia in rat spared nerve injury (SNI) and chronic constriction injury (CCI) models. Pain 115: 382-389, 2005.

HRUBÁ L, SCHUTOVÁ B, ŠLAMBEROVÁ R, POMETLOVÁ M: Does cross-fostering modify the impairing effect of methamphetamine on postnatal development of rat pups? Prague Medical Report 109(1): 50-61, 2008.

INGELMO PM, FUMAGALLI R: Neuropathic pain in children. Minerva Anestesiol 70: 393-398, 2004.

KALINCHEV M, EASTERLING KW, HOLTZMAN SG: Repeated neonatal maternal separation alters morphineinduced antinociception in male rats. Brain Res Bull 54: 649-654, 2001.

KIM SH, CHUNG JM: An experimental model for peripheral neuropathy produced by segmental spinal nerve ligation in the rat. Pain 50: 355-363, 1992.

LANCASTER FE, PHILLIPS SM, PATSALOS PN, WIGGINS RC: Brain myelination in the offspring of ethanoltreated rats: in utero versus lactational exposure by crossfostering offspring of control, pairfed and ethanol treated dams. Brain Res 309: 209-216, 1984.

LEE DH, CHUNG JM: Neuropathic pain in neonatal rats. Neurosci Lett 209: 140-142, 1996.

LIU D, CALDJI C, SHARMA S, PLOTSKY PM, MEANEY MJ: Influence of neonatal rearing conditions on stressinduced adrenocorticotropin responses and norepinepherine release in the hypothalamic paraventricular nucleus. J Neuroendocrinol 12: 5-12, 2000.

LOMBARD MC, NASHOLD BS, JR., ALBE-FESSARD D, SALMAN N, SAKR C: Deafferentation hypersensitivity in the rat after dorsal rhizotomy: a possible animal model of chronic pain. Pain 6: 163-174, 1979.

MAILIS A: Compulsive targeted self-injurious behaviour in humans with neuropathic pain: a counterpart of animal autotomy? Four case reports and literature review. Pain 64: 569-578, 1996.

MARTIN JC, MARTIN DC, RADOW B, SIGMAN G: Growth, development and activity in rat offspring following maternal drug exposure. Exp Aging Res 2: 235-251, 1976.

MARWICK C: NIDA seeking data on effect of fetal exposure to methamphetamine. JAMA 283: 2225-2226, 2000.

MCCLURE WO, ISHTOYAN A, LYON M: Very mild stress of pregnant rats reduces volume and cell number in nucleus accumbens of adult offspring: some parallels to schizophrenia. Dev Brain Res 149: 21-28, 2004.

MEANEY MJ: Maternal care, gene expression, and the transmission of individual differences in stress reactivity across generations. Annu Rev Neurosci 24: 1161-1192, 2001.

MURILLO-FUENTES L, ARTILLO R, CARRERAS O, MURILLO L: Effects of maternal chronic alcohol administration in the rat: lactation performance and pup's growth. Eur J Nutr 40: 147-154, 2001.

NARAYANAN CH, FOX MW, HAMBURGER V: Prenatal development of spontaneous and evoked activity in the rat (Rattus norvegicus albinus). Behaviour 40: 100-134, 1971.

OBERLANDER TF, GRUNAU RE, FITZGERALD C, PAPSDORF M, RURAK D, RIGGS W: Pain reactivity in 2month-old infants after prenatal and postnatal selective serotonin reuptake inhibitor medication exposure. Pediatrics 115: 411-425, 2005.

PLOGHAUS A, NARAIN C, BECKMANN CF, CLARE S, BANTICK S, WISE R, MATTHEWS PM, RAWLINS JN, TRACEY I: Exacerbation of pain by anxiety is associated with activity in a hippocampal network. $J$ Neurosci 21: 9896-9903, 2001.

RODIN BE, KRUGER L: Deafferentation in animals as a model for the study of pain: an alternative hypothesis. Brain Res 319: 213-228, 1984.

ROSSITCH E JR, OAKES WJ, OVELMEN-LEVITT J, NASHOLD BS, JR.: Self-mutilation following brachial plexus injury sustained at birth. Pain 50: 209-211, 1992.

ŠLAMBEROVÁ R, SZILAGYI B, VATHY I: Repeated morphine administration during pregnancy attenuates maternal behavior. Psychoneuroendocrinology 26: 565-576, 2001. 
ŠLAMBEROVÁ R, BAR N, VATHY I: Long-term effects of prenatal morphine exposure on maternal behaviors differ from the effects of direct chronic morphine treatment. Dev Psychobiol 43: 281-289, 2003.

ŠLAMBEROVÁ R, CHAROUSOVÁ P, POMETLOVÁ M: Maternal behavior is impaired by methamphetamine administered during pre-mating, gestation and lactation. Reprod Toxicol 20: 103-110, 2005.

ŠLAMBEROVÁ R, CHAROUSOVÁ P, POMETLOVÁ M: Methamphetamine administration during gestation impairs maternal behavior. Dev Psychobiol 46: 57-65, 2005.

ŠLAMBEROVÁ R, RILEY MA, VATHY I: Cross-generational effect of prenatal morphine exposure on neurobehavioral development of rat pups. Physiol Res 54: 655-660, 2005.

ŠLAMBEROVÁ R, POMETLOVÁ M, CHAROUSOVÁ P: Postnatal development of rat pups is altered by prenatal methamphetamine exposure. Prog Neuropsychopharmacol Biol Psychiatry 30: 82-88, 2006.

ŠLAMBEROVÁ R, POMETLOVÁ M, ROKYTA R: Effect of methamphetamine exposure during prenatal and preweaning periods lasts for generations in rats. Dev Psychobiol 49: 312-322, 2007.

SÖDERPALM A, NIKOLAYEV L, DE WIT H: Effects of stress on response to methamphetamine in humans. Psychopharmacology 170: 188-199, 2003.

STERNBERG WF, RIDGWAY CG: Effects of gestational and neonatal handling on pain, analgesia, and stress behavior of adult mice. Physiol Behav 78: 375-383, 2003.

SWEET WH: Animal models of chronic pain: their possible validation from human experience with posterior rhizotomy and congenital analgesia. Pain 10: 275-295, 1981.

TSENG SH: Suppression of autotomy by N-methyl-D-aspartate receptor antagonist (MK-801) in the rat. Neurosci Lett 240: 17-20, 1998.

VACULÍN Š, ROKYTA R: Effects of anesthesia and nociceptive stimulation in an experimental model of brachial plexus avulsion. Physiol Res 53: 209-214, 2004.

VACULÍN Š, FRANĚK M, ANDREY L, ROKYTA R: Self-mutilation in young rats after dorsal rhizotomy. Neuroendocrinol Lett 26: 25-28, 2005.

VAVŘÍNKOVÁ B, BINDER T, ŽIVNÝ J: Characteristics of a population of drug dependent pregnant women in the Czech Republic. Ceska Gynekol 66: 285-291, 2001.

VORHEES CV: A fostering/crossfostering analysis of the effects of prenatal ethanol exposure in a liquid diet on offspring development and behavior in rats. Neurotoxicol Teratol 11: 115-120, 1989.

VORONINA TA, CHOBANOV NG, MOLODAVKIN GM, ZHUKOV VN: Increased anxiety and reduced pain sensitivity in offspring of rats after prenatal morphinization. Bull Exp Biol Med 118: 844-846, 1994.

WHITAKER-AZMITIA PM: Serotonin and brain development: role in human developmental diseases. Brain Res Bull 56: 479-485, 2001.

WILDER RT, BERDE CB, WOLOHAN M, VIEYRA MA, MASEK BJ, MICHELI LJ: Reflex sympathetic dystrophy in children. Clinical characteristics and follow-up of seventy patients. J Bone Joint Surg Am 74: 910-919, 1992.

WONG CS, CHERNG CH, TUNG CS: Intrathecal administration of excitatory amino acid receptor antagonists or nitric oxide synthase inhibitor reduced autotomy behavior in rats. Anesth Analg 87: 605-608, 1998.

WOOD G, MARCOTTE ER, QUIRION R, SRIVASTAVA L: Strain differences in the behavioural outcome of neonatal ventral hippocampal lesions are determined by postnatal environment and not genetic factors. Eur $J$ Neurosci 14: 1030-1034, 2001.

YAMAMOTOVÁ A, ŠLAMBEROVÁ R, JEDLIČKA M, JAKUB T: Gender differences in nociception in adult rats prenatally treated with methamphetamine Homeostasis 43: 99-101, 2004.

YAMAMOTOVÁ A, ŠLAMBEROVÁ R: The effect of cross-fostering on nociception in prenatally stressed and methamphetamine-treated rats. Fifth Conference of the Czech Neuroscience Society, Prague, 2005, p 146.

YAMAMOTOVÁ A, FRANĚK M, VACULÍN Š, ŠŤASTNÝ F, BUBENÍKOVÁ-VALEŠOVÁ V, ROKYTA R: Different transfer of nociceptive sensitivity from rats with postnatal hippocampal lesions to control rats. Eur $J$ Neurosci 26: 446-450, 2007.

YASHPAL K, FISHER K, CHABOT JG, CODERRE TJ: Differential effects of NMDA and group I mGluR antagonists on both nociception and spinal cord protein kinase $\mathrm{C}$ translocation in the formalin test and a model of neuropathic pain in rats. Pain 94: 17-29, 2001. 
YOSHIMURA M, YONEHARA N: Alteration in sensitivity of ionotropic glutamate receptors and tachykinin receptors in spinal cord contribute to development and maintenance of nerve injury-evoked neuropathic pain. Neurosci Res 56: 21-28, 2006. 